\title{
The Role of Schema in Constructing Cross-cultural Minds for Students in Local Universities $^{*}$
}

\author{
Lijuan Li \\ Yibin University, Yibin, China
}

\begin{abstract}
Students studying and living in local universities find themselves failing in conducting fluent communication with people with different cultural backgrounds, due to the rare access to direct interactions with foreigners in person. Hence, to change that situation and help them construct cross-cultural minds is severely necessary. Abundant of achievements on cross-cultural communication have been reached, and a lot of rewards in the research have been granted to those studies analyzed, discussed and interpreted from the perspective of social-psychology, which can not propose an appropriate and efficient approach to constructing cross-cultural minds for students in the local universities. The studies from the perspective of cognitive process and more specifically the schema theory, however, can claim due attention to understand and construct the procedure of intercultural communication where multi-cultures are represented, processed and accommodated. This work is intended to address the issues of how students can efficiently obtain knowledge, how multicultural knowledge can be effectively acquired by students, and how beliefs can be shared and multicultural minds constructed finally.
\end{abstract}

Index Terms - cross-cultural communication, schema theory, local Universities

Nowadays there is no research of culture without the prefix multi- or cross-, since the world has become globalized and internationalized, and being a cosmopolitan is no longer a hypothesis in scholars' discussion. This is mostly true in the policy-opening, economy-developed and challenge-possible areas while the situation in the local areas presents another picture in spite of the convenience of the availability of internet, media and transportation. An important fact is that an individual's acquisition of knowledge is varied according to his/her accessibility to the intellectual world and society at large. Students living and studying in remotely located areas thus can not enjoy the convenience of international communication at hands as far as the foreigner's visits are concerned. What is worse is that they may become narrow-minded and incapable for the challenging culture-integrated society because of the limitation of the accessibility to experiencing an open internationalized environment, even though they can form some vague sense of the globalized pace of the world across a range of their social interactions online. Numerous researches about cross/inter-cultural communication have been done, abundant of achievements have been reached, and especially a lot of rewards in the research have been granted to those studies analyzed, discussed and interpreted from the perspective of social-psychology. The founding in the studies, obtained by means of observing and concluding the inter-culture participants' behaviors, to some extent addresses the questions of what intercultural-communication involves and how most individuals proceed in the course of communicating with people with different cultural backgrounds. It contributes a lot to the students with the accessibility of experiencing international communication at their convenience, the students living in first-tire cities for example. For students living in remotely located local universities, to help them construct cross-cultural minds is severely necessary and the efficient approach to that is to go through understanding the cognitive processes where culture is accommodated, represented, and processed.

\section{Cognition And Culture}

Cross-culture acquisition calls for not just the knowledge informed in books and the awareness inspired by other mass media products, but more the accessibility of experiencing multi-cultural communication. To understand this point, the definition of culture needs to be reinforced. Many ways are used to express what culture is and how it is composed. It is thought that culture is the consequence of material and spiritual civilization, while another view emphasizes its connection with human being where culture, containing knowledge of the world, beliefs, arts, morals, laws, and customs, is integrated in man's capacity and convention. Anthropologist Ralph Linton regards culture as the whole lifestyle of a society. Some scholars classify culture into two distinct branches; one is the "CULTURE" which reflects the very aspects of civilization, including literature, art, music, architecture, philosophy, and science etc; the other one is "culture" which concretely expresses the conduction of the living world, including the traditional custom, mode of life, standard of behavior, social convention, code of conduct, social connection etc.

\footnotetext{
* This paper is one of the achievements of the programme "How to Improve the Communicative Competence of College Students in Classes" (17SD0620) funded by Education Office of Sichuan Province.
} 
The cognitive linguistics led by Lakoff and Langaker describe culture is where one language is shaped, and the connections within a language lay clues for mankind to discover the nature of the world through the step-by-step recognition of an individual's mental cognitive process. They believe that man's cognition of the world is gradually and dynamically formed in one's worldly experiment which is influenced by culture context. During the formation an individual goes through the developing cognitive process, from the actual experiment to abstraction, categorization, conceptualization, mapping, metaphor/metonymy, which meanwhile shapes the language system in a certain cultural context. The experimentalism derived from cognitive linguistics shed lights not only on the understanding of the relationships between language and culture, but more on the inspiration of man's description of the world, culture included, and on the direction of intercultural study.

Recent researches on intercultural communication are mainly focused on the nature and components of culture as well as the modes of cross-culture, all of which post cognitive issues in a core place. The study of culture is indispensable from the course of cognition. In terms of social psychology, the term "empathy" is picked to versify one's social and mental involvements in his/her cognitive activities. It includes cognitive component, affective component and communicative component, among which the cognitive component is the foundation. As for the literature of the competence of intercultural communication, one conclusion has been made by numbers of relevant scholars that cognition, affection and social performance are the three major elements, and that culture is acquired not only from cognition but also from affection. At the same time, it is restated that culture is formed upon the interactive consequence of cognition and action, although the meme theory in culture study emphasizes culture's mimic function. All the above make one clear phenomenon where cognition plays a decisive role in building one's language and culture sense, which in return develop one's process of cognition.

The connection between cognition and culture has been explained in many scholars' literatures, and some of the works are done on cognition from the perspective of culture while some other works are made to explain culture from the perspective of cognition. The two interact with each other: the development of culture depends on the process of cognition, which is strictly confined to culture. (Perez -Arce, 1997) With the interaction between culture and cognition, mankind forms a pattern of knowing, understanding and explaining the objective world. The diverse processes of the formation define that people in different cultures will have varieties of thinking models, ethic values, social behaviors and language forms, which constitute the main contents of the study of intercultural communication.

Culture is derived from experiment as language is, on the basis of which man formulates his/her cognition of the world. The essential difference among various cultures can be attributed to the disparate and distinct ideas, images, and schemas constructed in different living environment, and to the diverse means metaphors/metonymies take to express ideas and describe things. Their differences displayed in language are the varieties of words, writing, pronunciation, sentence structures and grammar systems. In other aspects of culture, the customs, social behaviors, value systems, ways of thinking are differentiated, and they can even be detailed to their building styles, art types and groups of religions. The roots for the kaleidoscope of cultures lie in that people in different groups take different approaches to knowing and exploring the world, in other words in the different cognitive processes. Many linguists believe that one's cognition of the world is cultivated on his/her personal experiment in the living world, based on which the sequential processing of cognition moves to categorization, concept, images, and further more the similar images are abstracted into schemas and schematic network. For the different schemas and images, different cultures take different language forms to express themselves. In spite of the overall diversities of cognitive processes and cultures, it is still possible for individuals to achieve intercultural communication, because the schema abstracted in one's mental space can be grounded and referred precisely through language down to the actual objects or things in the world. Intercultural communication is a dynamic process, during which individuals constantly accommodate their cognitive structures, and understand the differences of categorizations, images, schemas, metaphors and metonyms in other cultures because of the different cognitive processes, so as to come true the share of knowledge and beliefs. (Lee , B .P .H, 2007)

\section{SCHEMA THEORY}

Schema, a kind of background knowledge about the world obtained by individual through experiment, is of great significance in one's comprehension of the world. In the course of cross-cultural communication, the absence and contradiction of schema in individuals with different cultural backgrounds post the most common and negative obstacles for mutual understanding, especially for those having difficulties in gaining access to build multicultural interactions and connections.

The concept of schema was put forward originally by Bartlett (1932), a follower of Gestalt psychology, to account for how information and events in stories and events are represented in memory for further recall. Bartlett (1932) believed that when the relevant information in memory is referred one can understand and recall the context of past experience. Then the term "schema" is used in the description and discussion of one's memory, especially in the representation of one's past experience. Bartlett, however, did not further explore the nature of the schema in this area. It is until the 1970s and 1980s that with responding to the advances in computer science and artificial intelligence at that time, researchers did not begin to raise interests in the discoveries of modeling human cognition in the field of artificial intelligence, and the schema theory was adopted again and developed as a theoretical framework to describe the structure and the role of knowledge in the mind (Minsky, 1975; Schank, 1982; Schank \& Abelson, 1977). 
The notion of Schema theory contributes a great deal to the study of cognitive psychology, by providing new and exciting ideas and ways in the description, explanation, and interpretation of the developments in one individual's cognitive process, such as inferencing, remembering, reasoning, and problem solving, and served as an impetus for a large volume of experimental research in learning, comprehension, and memory (Schallert, 1991).

The applications of schema theory have been further widely taken in every field of cognitive studies. In various domains, the concept of schema can find itself taking different forms to describe and explain the organization of knowledge and events, in the synonyms as "frames" (Minsky, 1975), "scripts" (Schank \& Abelson, 1977), "plans" (Schank, 1982). It has also been broadly used in linguistics and metalinguistics to describe the structure and organization of one language, with the result that a number of specialized terms such as "story schemata" (Mandler, 1978), "sentence schemata" (Winograd, 1983), "textual schemata" (Swaffar, 1988), "formal/rhetorical schemata," "content schemata" (Carrell, 1984), and "symbolic schemata" (Oller, 1995) has appeared in the relevant literature. The overflow of the concept of schema has been taken as one of the major problems because of its frequency and diversity; However, through all of these fields of study, the theory develops its major strengths in the study of knowledge's cognitive process, more specific in the insights it provides to understand the structure of knowledge and the way knowledge is represented and used in learning, comprehension, and inferencing (Nassaji, 2007). The delivering of separate schema, the picture of a set of knowledge in an individual's mind, transfer the information in one event or one thing within and cross minds when the knowledge is presented, regressed, understood and even inferred.

For the prestigious specialty of the schema theory in explaining one's cognitive process, the theory can answer the overwhelming questions of inter-cultural study for the students in remotely located local universities: (a) how multicultural knowledge is represented for them in class: (b) how multicultural knowledge is understood by them in their mind: and (c) how beliefs are shared and multicultural minds constructed finally. In the following, I will discuss the role played by Schema in helping construct cross-cultural minds for students in local universities.

\section{The Role of Schema in Constructing Cross-Cultural Minds For Students In Local Universities}

Living in a place compelled with the denial of actual cross-cultural performance, students, more or less, feel segregated from the fast growing internationalized society and begin to lose confidence in building intercultural communication competence. The above three major issues are designed for helping them realize the current problems and work out practical ways to solve them; the first one is concerned with the initial step of cognitive process, that is how students can efficiently obtain knowledge; the second one is designed for the discussion of the role of affection played in cognitive process, which answers the question of how multicultural knowledge can be effectively acquired by students; and the third one is directed to the students' performance, the last step of cognitive process, on how beliefs can be shared and multicultural minds constructed finally.

\section{A. Mutual Knowledge}

Schema seems like magnets in that they connect many diverse elements of cultural knowledge. Like religious schema or linguistic schema, cultural schema is taken as images collected, selected or even created by an individual within his/her cognitive competence to evoke in observers a particular frame of thought or a particular frame of mind in a powerful and differentiated way. The potency and distinctiveness of schemas make the students without any experience of intercultural communication possible candidates to cultivate multi-cultural minds and spread activation in a network of cultural constructs. The construction of schema for students in that condition is supposed to start from knowledge processing and sharing followed. Knowledge is different from belief in ways as differentiated by B .P .H .Lee (2007) in his literature. He believes in establishing common ground, mutual knowledge will be developed into background knowledge with efficient clues of information and chances of interaction, and then further abstracted into shared beliefs which play a decisive role in realizing fluent conversation and communication of any kind. This idea is quite inspiring for the construction of intercultural minds for students in that special phenomenon.

B.P.H.Lee (2007) firstly distinguishes 'belief' and 'knowledge'. Even though they are often used interchangeably, in their use, they differ in terms of how securely the individual holds them. Lee and his team give examples to show the difference in the degree of certainty hold by individuals. Knowledge in some way is the information being able to be kept or memorized in mind while belief is the concept shaped like the schema in one's mind, as a result of summarizing all the relevant information consciously or unconsciously acquired. That accounts for why belief holds more conviction in mind compared with knowledge.

For an individual to share beliefs and knowledge, the basic structural component of man's cognition, can not be underestimated and neglected. For the students from the local universities, subjects or courses about the knowledge of other cultures are great attraction to them, especially the knowledge about the very detailed description of their daily life in a different culture, mostly because of the curiosity for the exploring the unknown world to find any other different possibilities. It is necessary and pragmatic for the students in those areas to get touch with knowledge of other culture in every aspect through all kinds of measures, by explaining, comparing, listing, reporting, discussing, and concluding, for example. By explanation and cooperation, intercultural communication learners can get the share of information in the common knowledge; by listing and reporting, they can analyze the information contained in certain knowledge; and by discussion and conclusion, they process and gain the knowledge required. When the knowledge relevant to intercultural 
communication, including the two parts of culture and communication, is well presented to the students, they will successfully have the share of mutual knowledge and climb up at the first step in their schema construction for intercultural communication.

\section{B. $\quad$ Shared Belief}

B.P.H.Lee(2007) believes that the notion of shared belief can answer the question of how people seem to be able to establish common understanding in apparently effortless day-to-day interactions in rapid conversation. Shared belief involves no more than a few number of steps and issues (such as conversation context, common sense in a particular culture, convention of a society,), and it is this psychologically viable notion that can explain how people are able to communicate effectively in daily rapid conversation. Across a range of statistic analysis, B.P.H.Lee (2007) reinforces his idea that it is shared belief that plays a more significant role than mutual knowledge does in successful communication. The truth of the idea can be proved by the fact that individuals commanding amount of knowledge of intercultural communication will fail in effectively communicating with other individuals with different cultural backgrounds. Shared belief is the consequence of subjective judgment on the world, which is originated from one's cognitive process. According to the views in linguistics, the concept in one's mind is processed on the perception and categorization of the world. At the moment when the concept is impressed or abstracted, a particular schema of the perception of the reality appears in one's brain. The construction of schema is influenced by varieties of social environmental factors, so the schemas of the same concept may be different among individuals with distinct cultural backgrounds. This explains the cross-culture shock commonly confronting intercultural communicators because of the deficiency and contradiction of schemas in different cultures. Any sort of schema is affected by culture, and any kind of schema is a cultural schema.

Both belief and schema are the comprehensive abstraction of the perception of the world, which makes it hardly practical for students in local universities to get a true-to-life picture of the world in other cultures. TV shows, movies, classic literature, and other traditional or modern media tools are used mainly for fun and entertainment not for presenting a real world of that culture(even though there are some that can demonstrate the world in a special way), which is misleading the way we percept other culture. On the contrary, the documentary, historic data, records and cases, or even the pictures twittered online, which keep one's life activities and true affections, are useful to some extent. All the details of description of the world and culture are essential in helping abstract reliable belief and schema of that alien culture, which is favorable for the students in that special condition to build correct connections with the outside world.

\section{Common Ground}

Besides the issue of the 'mutual knowledge - shared belief' is essential in successful communication, the notion of common ground (B.P.H.Lee, 2007) needs further attention. The main concerns for the study of common ground are what its nature is, what its relation with mutual knowledge, shared belief, and what the role of this common ground is in successful communication. Various answers have been presented, and still as yet no general common sense has been reached amongst scholars who are studying in the diverse disciplines of psychology, linguistics, philosophy, and even Artificial Intelligence.

The term 'common ground' has been used in place of other related concepts by various scholars. Sometimes, common ground is equivalent to mutual knowledge. Clarke (1992) states that he uses the term 'common ground' in place of 'mutual knowledge' to avoid the confusion (i.e., the infinite regression debate) related with mutual knowledge.

The discussion above informs us of the accurate current situation with the use of the term 'common ground'. To be specific, the lack of precision in the use of the term reflects a fundamental confusion at the conceptual level between the notion of common ground and the other notions associated with it. This conceptual confusion lies in part in the lack of distinction made between knowledge and belief (B.P.H.Lee, 2007).

B.P.H.Lee (2007) and his team remain to support that 'common ground', if used as an all-embracing term, can be conceptualized in terms of progressive steps of attainment. In sum then, common ground which has been established in the discourse comprises beliefs and knowledge and establishes them as shared. Thus, it is clear to say that common ground is the result of interaction with presence of both shared beliefs and knowledge.

For the landing on a common ground in the discourse of intercultural communication, the interactive communication is indispensible. Students from the universities located in a remote region are supposed to creatively build interactive cross-cultural communication online, because it is hard for them to have that offline. Definitely they can volunteer and be volunteered to cosplay with partners, but the outcome may not go as pleasant as they think, for the partners offline in the real situations to a large extent share the same cultural knowledge and beliefs with themselves. Obviously only by conducting online or offline intercultural communication, can the students successfully land on the common ground and cultivate the cross-cultural minds.

\section{CONCLUSION}

It can be concluded that it is a temporary state not an ever-lasting trait to think and behave like a member of other culture. This state will take place when schema of the host culture and the shared knowledge and beliefs are accessible. 
I submit that students undergoing cultivation of cross-cultural minds and acculturation, to some extent, manage the process by controlling the accessibility of cultural constructs. Students desiring to promote their intercultural communication competence quickly surround themselves with knowledge, symbols, situations and beliefs that prime the meaning system of the host culture and build a precise and clear schema in their mind. Active processes of priming oneself and grounding in the cross-culture communication may help students in that special situation in their ongoing effort to promote their intercultural communication competence.

Future research should be investigated into the authentic data collected in the procedures when students navigate intercultural transitions, the study of which, I believe, will reveal what and how students from local universities actually do in real situations to obtain shared beliefs, establish common ground, and build cross-cultural minds.

\section{REFERENCES}

[1] Bartlett, F.C. Remembering. (1932). Cambridge: Cambridge University Press.

[2] Bransford, J. D., \& Franks, J. J. (1971). The abstraction of linguistic ideas. Cognitive Psychology, 2, 331-350.

[3] Carrell, P. L. (1984). Evidence of a formal schema in second language comprehension. Language Learning, 34, 87-112.

[4] Clark, Herbert H. (1992). Arenas of language use. Chicago, IL: The University of Chicago Press and Center for the Study of Language and Information.

[5] Higgins, E. T. (1996). Knowledge activation: Accessibility, applicability and salience. In E. T. Higgins \& A. E. Kruglanski (Eds.), Social psychology: Handbook of basic principles. New York: Guilford Press, 58-97.

[6] Lee, B.P.H. (2001). Mutual Knowledge, Background Knowledge and Shared Beliefs: Their Roles in Establishing Common Ground. Journal of Pragmatics, 5, 33-47.

[7] Mandler, J. M. (1978). A code in the node: The use of a story schema in retrieval. Discourse Processes, 1, 14-35.

[8] Minsky, M. A. (1975). A framework for representing knowledge. In P. H.Wiston (Ed.), The psychology of computer vision. New York: McGraw Hill, 211-277.

[9] Nassaji Hossein.(2007).Schema Theory and Knowledge-Based in Second Language Reading Comprehension: A Need for Alternative Perspectives Language Learning, 6, 79-113.

[10] Oller, J. W. (1995). Adding abstract to formal and content schemata: Results of recent work in Peircean semiotics. Applied Linguistics, 16, 273-306.

[11] Perez -Arce, Patricia. (1997). The Influence of Culture on Cognition, Archives of Clinical Neuropsychology, 7, 153-174.

[12] Samour, L.el al. (2000). Communication between Cultures. Peking: Foreign Language Teaching and Research Press \& Brooks/Cole/Thomson Learning Asia.

[13] Schallert, D. L. (1991). The contribution of psychology to the teaching of the language arts. In J. Flood, J. Jensen, D. Lapp, \& J. R. Squire (Eds.), Handbook of research on the English language arts. New York: Macmillan, 156-173.

[14] Schank, R. C. (1982). Dynamic memory: A theory of reminding and learning in computers and people. Cambridge: Cambridge University Press.

[15] Schank, R. C. \& R. Abelson.(1977). Scripts, Plans, Goals and Understanding. Hillsdale, NJ: Erlbaum.

[16] Swaffar, J. K. (1988). Readers, texts, and second languages: The interactive process. Modern Language Journal, 72, $123-149$.

[17] Winograd, T. (1983). Language as a Cognitive Process. Syntax. Reading, MA: Addison-Wesley, 1, 231-245.

[18] Wyer, R. S., \& Srull, T. K. (1986). Human cognition in its social context. Psychological Review, 93, 322-359.

Lijuan Li was born in Guang'an, China in 1984. She received her master degree in English language and literature from the School of Foreign Languages, Sichuan Normal University, Chengdu, China in 2009.

She is currently a lecturer in the School of Foreign Languages, Yibin University, Yibin, China. Her research interests include cross-cultural communication, British and American literature. 